\title{
Studies on Determination of Tin and Lead in Alloys for Organ Pipes by GD-OES and Detecting Capability of Charge Coupled Device (CCD)
}

\author{
Young-Sang Kim, ${ }^{\star}$ Detlef Schiel, ${ }^{\ddagger}$ Hans Warlimont, ${ }^{\ddagger}$ and Volker Hoffmann ${ }^{\ddagger}$ \\ Department of Adwanced Material Chemistry, Korea Vniversitv, Jochiw'on 339-700, Korea \\ ${ }^{\dagger}$ Physikalisch Technische Bundesanstalt(PTB). Bundesallee 100. Braunschweig 38116. Germany \\ ${ }^{\ddagger}$ Leibniz-Ihstitute for Solid State and Materials Research $(I F W)$. Helmholtzstrasse 20, Dresden 01069, Germany \\ Received February 12. 2004
}

Key Words: Glow discharge optical emission spectrometry (GD-OES). Charge coupled device (CCD). Organ pipe. Tin-lead alloy

In this work the determination of tin and lead in their alloys for use as organ pipe materials was performed by a glow discharge optical emission spectrometry (GD-OES) using charge coupled device (CCD) spectrometers. The lead and tin alloy has been used as a typical material for organ pipes since very long ago and are being used for the renovating of the old pipes at present. The choice is related to the tone of the note required from the pipe and occasionally to the wealth and generosity. In addition. the use of the alloy arises due to the unique acoustic properties of themselves and the micro-structural condition. The alloy: pipes have been made with as high a composition as $85 \%$ lead and $15 \%$ tin in the last hundred years or more. but the organ trade had the view that no alloy for organ pipes contain less than $25 \%$ tin and no alloy with less than $55 \%$ tin should be employed in really good work. ${ }^{1.2}$ Both elements are major constituents in the alloy. For the analy sis. a careful performance should be tried to decrease the error as well as the deviation in the determined results. Therefore. GD-OES was chosen as an analytical method in this work

On the other hand. X-ray fluorescence spectrometry is also well known to be a reproducible and reliable method for the determination of minor and major elements in solid and liquid samples. But the fluorescent intensity is significantly' influenced by a matrix effect ${ }^{3}$ so that it can not be a proper method for the organ pipe samples because of the big change of concentration for two kinds of elements. In GD-OES. GD sputters elemental atoms from the surface of solid samples to emit radiations. The matrix effect is not so serious on the emitted intensity because the spectral lines are emitted by the excitation of sputtered atoms or ions.

CCD used here has a possibility to display the detecting sensors with two-dimension so that it can be advantageous to detect nearly all elements simultaneously: Even though CCD has a relatively low sensitivity and high detection limit it has a flexibility to obtain total spectra of all more than $0.1 \%$ elements. And the combination of CCD and polychromator is possible in our instrument to compromise the sensitivity and versatility instead of the combination of polychromator and monochromator. Our instrument consists of three fibre optical spectrometers of $\mathrm{CCD}$ covering wavelength regions of $200-730 \mathrm{~nm}$. In order to test the performance and reliability of CCD-GD-OES seven kinds of sy'nthetic lead and tin alloys ( $\mathrm{J}$ _series) were analysed with five certified standards having wide range of $10-90 \mathrm{wt} \%$ concentration. After a precision and accuracy on obtained data were evaluated with the standard deviation and linearity of calibration curve. the determination of lead and tin was conducted in ten kinds of real old organ pipes (JO_series).

\section{Instrumental}

The instrument used was GDA 750 of Spectnuma Analy tik $\mathrm{GmbH}$ in which both of CCD and PMT systems were equipped as a spectrometer and detector. Three fibre optical CCD spectrometers are included in GDA 750 covering bandwidths of 200-400. 390-580 and $580-730 \mathrm{~nm}$. respectively: A polychromator of PMTs was equipped in this instrument as well. But only CCD system was used for this work. which had the number of about 6000 of pixel and resolution of $0.3 \mathrm{~nm}$. The spectra of full wavelength range could be repeatedly scanned with each scan time of 100 2000 milliseconds to decrease noise levels. And time resolution can be more than $300 \mathrm{msec}$.

The use of both DC and RF mode are possible for both of conductive and non-conductive samples. But specimens of lead-tin alloy were sputtered by DC mode in GD source of 4.0 and $2.5 \mathrm{~mm}$ diameter. The source of $4.0 \mathrm{~mm}$ diameter was used for synthetic samples (J_series) to evaluate the reliability of determinations. Especially: a small source of $2.5 \mathrm{~mm}$ diameter was used for the real organ samples (JO_series) because the alloy specimens not only were thin and small in size. but also had a low melting point of less than $200^{\circ} \mathrm{C}$.

\section{Methods}

The conditions were as followings: applied voltage $700 \mathrm{~V}$. current $10 \mathrm{~mA}$ and argon pressure about $2 \mathrm{hPa}$ for the use of $4 \mathrm{~mm}$ diameter source and $700 \mathrm{~V}$. $6 \mathrm{~mA}$. ca. $2.3 \mathrm{hPa}$ for 2.5 mum diameter source. The scan of $2000 \mathrm{msec}$ was repeated with 50 times (total 100 seconds) for each specimen. The variation of intensity depending on a discharging time could be observed with such repeated scans and the intensity was stabilized along with the increase of scan number. A specimen was cooled by a direct contact of flowing water on 
the backside of the specimen because the sample was thin and soft. The variation of intensity and intensity ratio was observed with Standard LSn60.

Five standard specimens were used for the calibration curve. Concentration of tin was $10,30,60.80$ and $90 \mathrm{wt} \%$, respectively, and the remained was lead in each standard. Three times of discharges were done for each standard to see the reproducibility of intensities. Seven kinds of synthetic samples (J_series, nominally $10,40,50,60,70,80$ and $90 \%$ tin) and ten analytical samples of old organ pipes (JO_series) as shown in Tables 1, 2 were analysed. The samples $\mathrm{JOOl}$ to JO04 were parts of one organ, which was produced by the Jehınlich. Samples JO5 to JO10 were taken from different organs built by Silbermann. And the reliability about obtained data were evaluated with error ranges and standard deviations.

\section{Results and Discussion}

At first, the selection of analytical lines is very important for the determination of analytical elements because the intensity ratio should be linearly related to the concentration ratio without any interference. The relative sensitivity and interference of analytical lines by a glow discharge have been already investigated and well known so that many wavelengths as well as other essential things were published. In an instruction manual of our instrument, the related information about analytical lines by a discharge is provided as a Speccalc file together with the nominations of NISI, NRL, Arc, ICP, and Spark. The spectra obtained in this work were not just the same as the spectra of the glow discharge, preferably more closed to mixed spectra of the discharge and ICP. The conditions used for the data basis were not given, but definitely different to the used one. Such phenomena seem to be due to the different sensitivity of $\mathrm{CCD}$ with PMT and the discharge by argon gas. Therefore, several lines were selected for each element to fix the best line as follows: $300.91,317.51$ and $645.35 \mathrm{~nm}$ for tin; 220.35, 368.33, 405.73 and $560.83 \mathrm{~nm}$ for lead. Before this selection, the wavelengths of spectral lines were calibrated by given programs in three wavelength regions of $200-400 \mathrm{~nm}, 390-$ $580 \mathrm{~nm}$ and $580-730 \mathrm{~nm}$. As a result, most of measured spectral lines were closed to the literature values.

As described in previous section, Sn 645.35 and $\mathrm{Pb} 220.35$ lines were fixed as the best combination and a $2.5 \mathrm{~mm}$ diameter source was used for the analysis of given unknown samples. Prior to a real analysis, the reproducibility of data, the linearity and standard deviation of regression, the applicability of this method, and so on were investigated with such conditions as $700 \mathrm{~V}, 10 \mathrm{~mA}, c a .2 .0 \mathrm{hPa}$ and $4 \mathrm{~mm}$ diameter source using five standards and seven synthetic samples ( $\mathrm{J}$ series). Three times of measurements were done at different positions for each standard to see the reproducibility of intensities and a calibration curve was prepared with all measured intensities of standards (see Fig. 1). That is, the intensity ratio of tin to lead was plotted versus the concentration ratio of them using $\mathrm{Sn} 645.35$ and $\mathrm{Pb} 220.35$. As shown in Figure I, the curve is completely linear with $R$

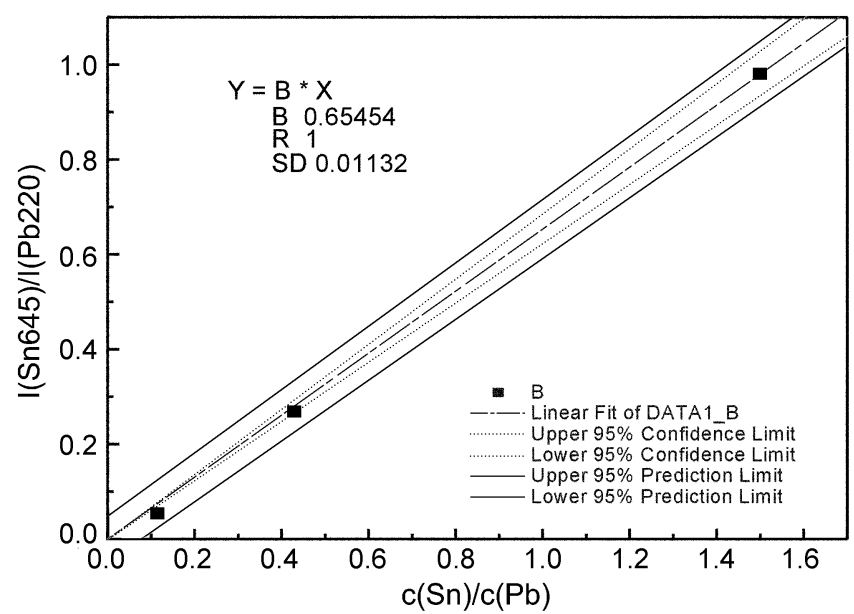

Figure 1. Calibration curve for the evaluation of the reliability: Conditions: 700 V. $10 \mathrm{~mA}$. ca. $2 \mathrm{hPa} .4 \mathrm{~mm}$ dia. cathode area.

value of $\mathrm{l}$ and the standard deviation for regression is $0.01 \mathrm{I}$, which indicates the relative standard deviation of $c a .2 .2 \%$ at the middle intensity ratio. And analytical results of synthetic samples obtained by other calibration curve of wide concentration range are indicated in Table 1.

Based on the obtained results of synthetic samples (J_series), samples were analysed by measuring the intensities under changed conditions such as $700 \mathrm{~V}, 6 \mathrm{~mA}, c a .2 .3$ $\mathrm{hPa}$, and $2.5 \mathrm{~mm}$ dia. source. Some specimens of organ pipes were thin and small in size and have a low melting point of less than $200^{\circ} \mathrm{C}$ so that a low current of $6 \mathrm{~mA}$ was applied in a source of small cathode area. On the assumption that the materials for organ pipes consisted of only tin and lead, the calibration curve was prepared by plotting the intensity ratio of tin to lead versus the concentration ratio (Fig. 2). And the analytical results for synthetic samples (J_series) and real organ pipe samples (JO_series) were obtained from this curve (Table 2).

The calibration curve is perfectly linear with $\mathrm{R}$ value of 0.99979 and the standard deviation of 0.04963 for the regression indicates a relative standard deviation of $1.7 \%$ at the middle intensity ratio on the curve. The analytical results of $\mathrm{J}$ series samples are consistent to the nominal values within the relative difference of 5\% except in J LSn 10 sample of low intensity. Therefore, the analytical results for the real organ pipe samples are expected to be accurate

Table 1. Analytical results obtained by above calibration curve

\begin{tabular}{|c|c|c|c|c|}
\hline $\begin{array}{l}\text { Syothetio } \\
\text { sample } \\
\text { numbor }\end{array}$ & $\begin{array}{c}\text { Nominal } \\
\text { concentration } \\
\text { of tin/wt } \%\end{array}$ & $\begin{array}{c}\text { Intensity ratio } \\
\{\mathrm{l}(\mathrm{St} 302) / \\
\mathrm{I}(\mathrm{Pb} 405)\}\end{array}$ & $\begin{array}{c}\text { Calculated } \\
\text { concentration } \\
\text { ratio }\end{array}$ & $\begin{array}{c}\text { Oblained } \\
\text { concentration } \\
\text { of tin } 1 \text { t } \%\end{array}$ \\
\hline I_LSSn10 & 10 & 0.044 & 0.128 & 11.3 \\
\hline I_LSSn40 & 40 & 0.188 & 0.545 & 35.4 \\
\hline I_LSS 50 & 50 & 0.303 & 0.878 & 46.8 \\
\hline I_J $\operatorname{Sin} 60^{\circ}$ & 60 & 0.429 & 1.243 & 55.4 \\
\hline I_ISSn70 & 70 & 0.830 & 2.406 & 70.6 \\
\hline I_J $\operatorname{Sin} 80$ & 80 & 1.653 & 4.791 & 82.7 \\
\hline $1 . \operatorname{Sin} 90^{\circ}$ & 90 & 2.843 & 8.240 & 89.2 \\
\hline
\end{tabular}




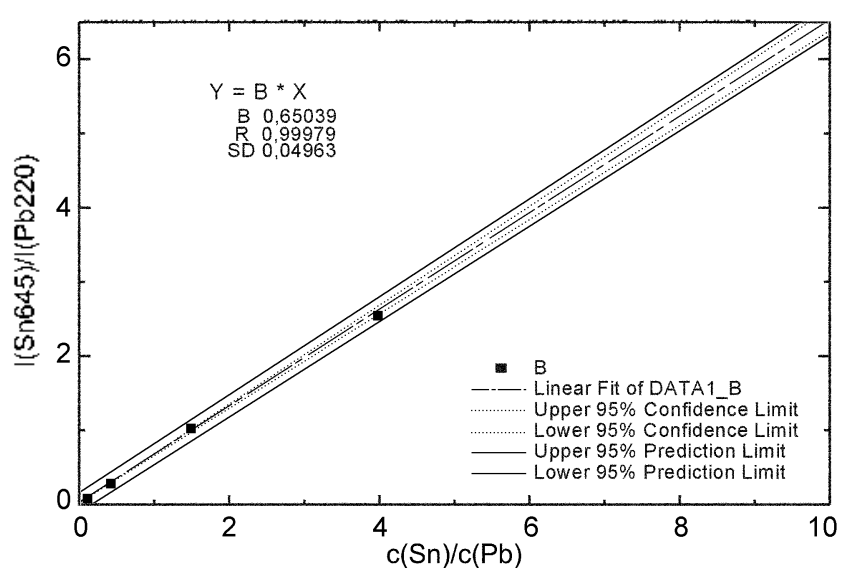

Figure 2. Calibration curves for the deternination of tin and lead in organ pipe samples. Conditions: $700 \mathrm{~V} .6 \mathrm{~m} \wedge .6 a .2 .3 \mathrm{hPa}, 2.5 \mathrm{~mm}$ dia. anode.

within a relative error of $5 \%$.

In addition, the intensities of two spectral lines used were measured five times at different position of one standard, LSn60, to obtain the relative standard deviation (RSD). The RSD was $7.22 \%$ for $\mathrm{Sn} 645.2 \mathrm{l}$ line and $5.57 \%$ for $\mathrm{Pb} 219.55$ line, respectively, but the RSD value for intensity ratio of them was $3.23 \%$. which was significantly lower than above values for intensities. Therefore, the analytical results can be expected with the reproducibility of within $5 \%$ RSD as a whole under the consideration of the RSD about the linear regression and the measured intensities at the different positions on a specimen.

In fact, absolute spectral intensities by such low conditions as $6 \mathrm{~mA}$ and $2.5 \mathrm{~mm}$ dia. anode were much weaker than by
Table 2. Analytical results of tin in real organ pipe samples (10 series) and synthetic samples (J-series)

\begin{tabular}{|c|c|c|c|}
\hline $\begin{array}{l}\text { Sample } \\
\text { mumber }\end{array}$ & $\begin{array}{c}\text { Nominal } \\
\text { concen- } \\
\text { trationsut } \%\end{array}$ & $\begin{array}{c}\text { Analytical } \\
\text { results } \\
\text { nt } \%\end{array}$ & Name of organ pipes \\
\hline JO01 & & 55.84 & I0 1819 Lauenstcin Oktave $2^{1}$ \\
\hline $\mathrm{JOO} 2$ & & 54.87 & 10) 1819 Lauenstcin Oktave $4^{1}$ \\
\hline JOO3 & & 52.95 & I0 1819 Lauenstcin Cimbel 2tach \\
\hline $\mathrm{JOO4}$ & & 43.42 & 101819 Lauenstein Spitzflöte $4^{\prime}$ \\
\hline $\mathrm{J} 005$ & & 88.26 & GSO 1748 Nassau Oktave 4' Prospckt \\
\hline J006 & & 85.51 & GSO 1748 Nassau Mixtur fach \\
\hline $\mathrm{J} 007$ & & 86.92 & GSO 1748 . Nassau Oklave 2' \\
\hline J008 & & 85.75 & GSO 1724 I ebusal Prinzipal 8" Prospekl \\
\hline Jo09 & & 20.77 & GSO 1724 I ebusia Gedackt \\
\hline J010 & & 92.83 & $\begin{array}{l}\text { (iSO } 1719 \text { Dom Freiberg } \\
\text { Prospektpleilen (1 ettrler-Orgel) }\end{array}$ \\
\hline I_ISSin 10 & 10.00 & 11.08 & \\
\hline$J \mathrm{LS}$ S1 40 & 40.00 & 40.14 & \\
\hline I_LSn50 & 50.00 & 49.18 & \\
\hline J_LSt160 & 60.00 & 60.07 & \\
\hline J $L S$ Sn 70 & 70.00 & 73.49 & \\
\hline J_LSn80 & 80.00 & 83.01 & \\
\hline J_LSn90 & 90.00 & 87.76 & \\
\hline
\end{tabular}

the higher condition of $10 \mathrm{~mA}$ and $4 \mathrm{~mm}$ dia. source (Fig. 3 . full spectra). That is, one third of high condition intensities were measured. Both intensity ratios are similar each other even though the plasına conditions are different. Such relationship can be compared between the curves of Figure $I$ and 2 .

But such analysis was done under the assumption that only two elements of tin and lead were present in the organ pipe materials. So the assumption should be confirmed to support these data. In order to confirm the absence of other elements

Spectrum A

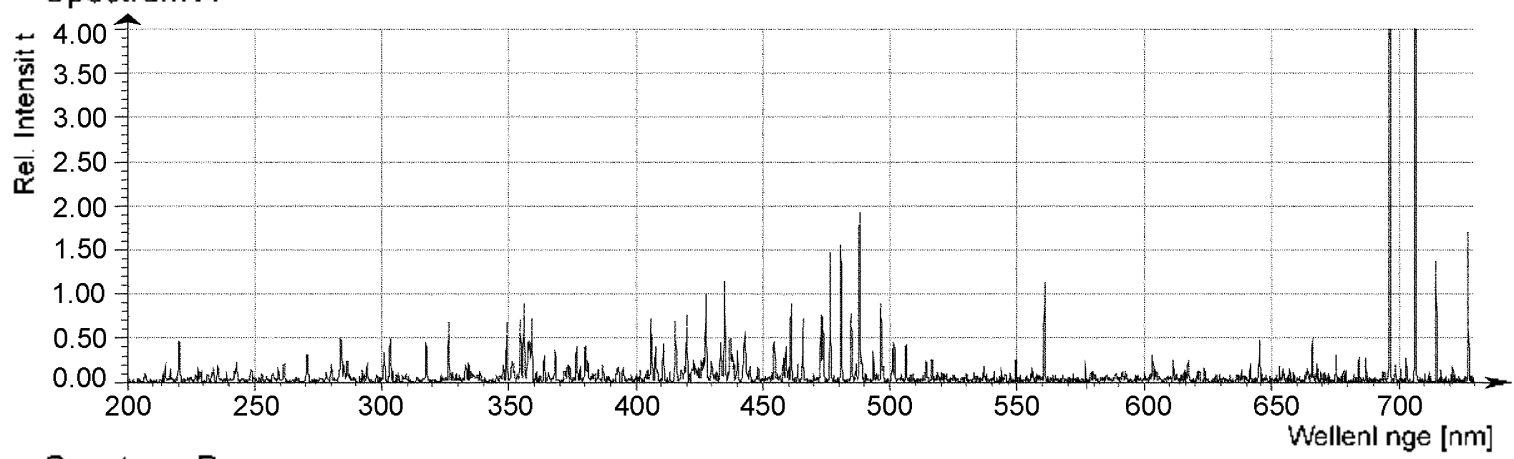

Spectrum B

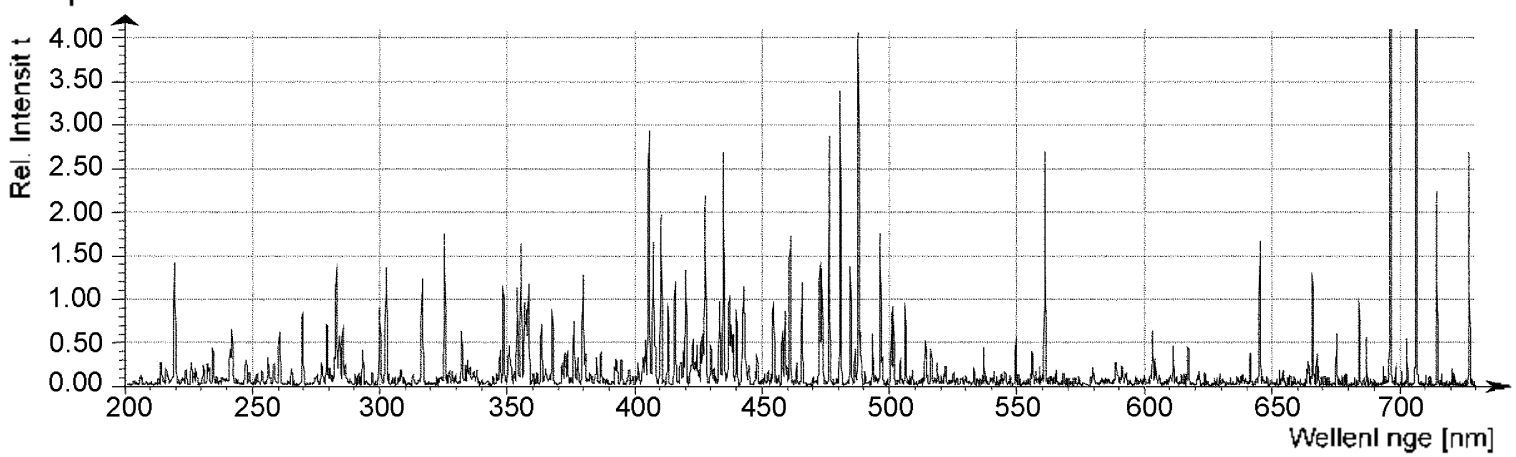

Figure 3. Full spectra of LSn60 standard. (A) 700 V. $6 \mathrm{~mA} .2 .5 \mathrm{~mm}$ dia. souree; (B) 700 V. $10 \mathrm{~mA} .4 .0 \mathrm{~mm}$ dia. source. 

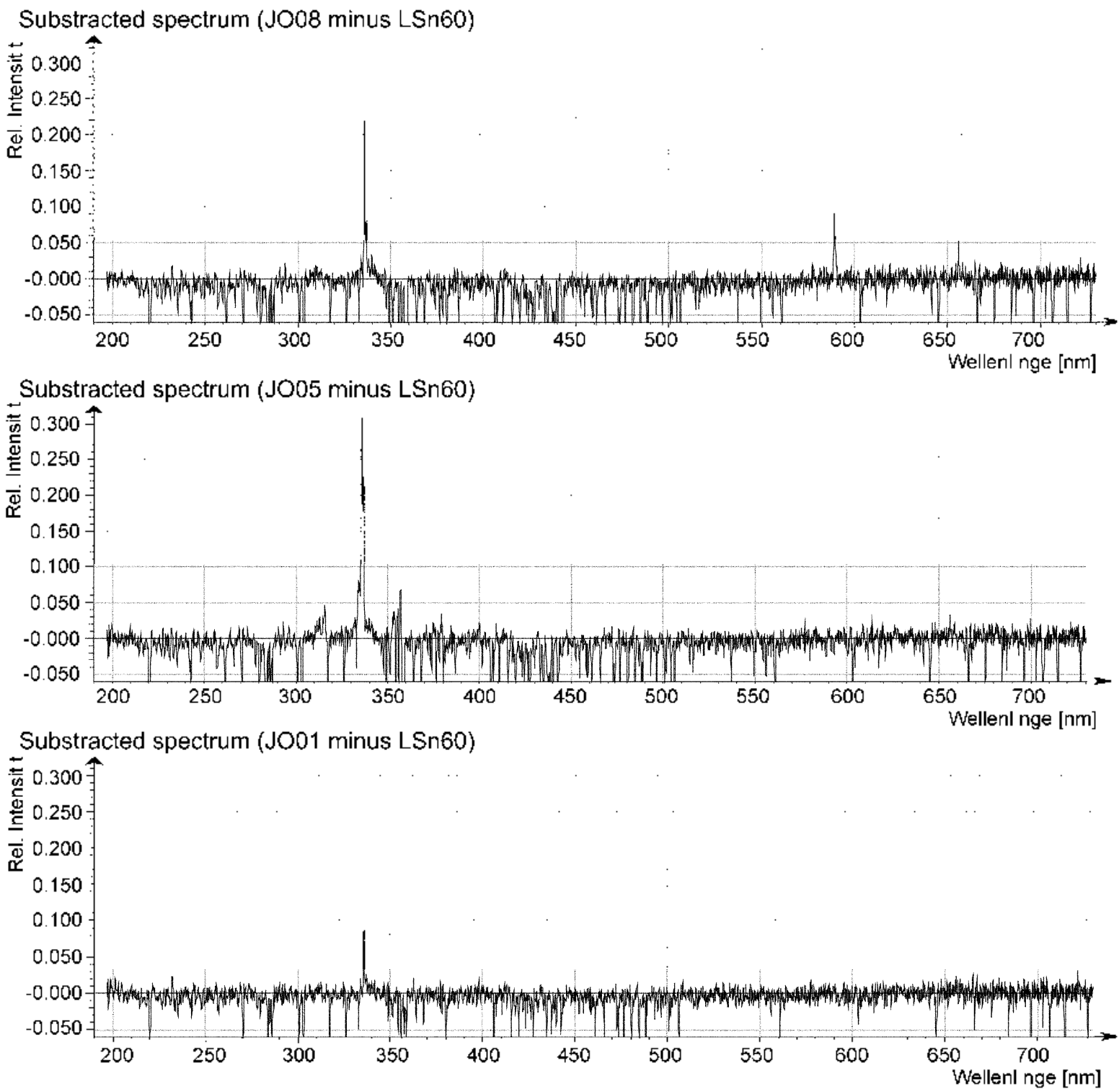

Figure 4. Subtracted spectra of several organ pipe samples. Spectrun of I Sn60 was subtracted trom three spectra of JO01, JO05 and IO08 samples.

in the samples, the full spectrum of standard (here, LSn60) was subtracted from analytical spectra, and the remained spectral lines were identified in the subtracted spectra (Fig. 4). As in Figure 4, most of lines were disappeared on subtracted spectra, but only several lines were remained in the wavelength region of $336-337 \mathrm{~nm}$ and around 589 and 656 nın. Several lines in the region of $336-337 \mathrm{~nm}$ are connected each other and closely similar to a molecular band. Probably, the band can be considered to be due to $\mathrm{CH}$ because the band gradually decreased and increased together with $\mathrm{C}$ lines at $589 \mathrm{~nm}$ and $\mathrm{H}$ line at $656 \mathrm{~nm}^{+}$Besides, the formation of $\mathrm{CH}^{\prime}$ radical could be presumed to be caused by organic coatings used at the production of the organ pipes.

In summary, CCD system had a relatively low sensitivity, but showed stable and reproducible intensities. Under low conditions such as $700 \mathrm{~V}, 6 \mathrm{~mA}$, and $2.5 \mathrm{~mm}$ diameter source, intensities of lead and tin in organ pipe samples were measured and their concentrations were obtained by a calibration curve method of intensity ratio and concentration ratio. The curve was linear with $R$ value of 0.99979 and the standard deviation of 0.04963 . The analytical results were in range of $20-90 \mathrm{wt} \%$ for tin and the remainder was the concentration of lead.

Acknowledgement. Mr. Jehmlich should be sincerely appreciated by authors for the provision of historical pipe organ samples and for helpful discussions.

\section{References}

1. Guruswamy. S. Hingineering Properties and Apptications of Lead Allows: Marecl Dekker. Inc.: New York. 2000: pp 479-480.

2. Morgan, I. Ifooper. B. Proc, $77^{\text {th }}$ Imemational Lead Conf. Venice. Italy, Vay 24 27, 1993: Paper 6.3.

3. Bertin. 1: P. Princinles and Practice of X-Ray Spectrometric Anatysis: l'lenum Press: Vew York-London. 1970: pp 501-527.

4. Spectroscopic Data Retative to Diatomic : Holecules. International Tables of Selected Cunstents: Pergamon Press: New York. 1970: p 89. 